\title{
Analysis on the Application of Network and Mobile Internet Tools in Daily Ideological and Political Education
}

\author{
Zhong-Tong LIU ${ }^{\mathrm{a}}$ and Fan-Gang MENG ${ }^{\text {* }}$ \\ College of Electrical and Information Engineering, Beihua University, Jilin, China \\ a21018582@qq.com , b28772282@qq.com \\ *Corresponding author: Fan-Gang MENG
}

Keywords: Network; Mobile Internet tools; teaching, application

\begin{abstract}
The rapid development of the network technology and the gradual popularization of the mobile Internet, the effective use of emerging network technology will effectively expand the breadth and the dimensions of Ideological and political education of the students in the colleges and universities.As the science and the technology developing recently, the network and the mobile Internet tools and the other information tools have already been integrated into all aspects of life, the network and the mobile internet tools have already covered every student in the universities and the colleges all over the world.Therefore, the effective use of these new technologies for ideological and political education has a long-term significance, that will effectively expand the breadth and the dimensions of Ideological and political education of the students who are in the colleges and the universities. In this paper , by analyzing the characteristics of the network and the mobile Internet tools .we are looking forward to find the entry point of using the Internet and the mobile Internet tools for the ideological and political education work,we are hoping that the Internet and the mobile Internet tools are able to be truly integrated into the ideological and political work which are able to provide an effective theoretical basis.Seize the opportunity to change, seize the forefront of the network era,make the ideological and political education into every corner of the university are the work content which the instructor must face today,only in this way we can in line with the times and advance with the times.
\end{abstract}

\section{Introduction}

The rapid development of the network technology and the increasing popularity of the mobile Internet, they have been opened a new era of the development of human information, the Internet and the hand-held terminal devices have became the main tools for people to get fragmentation of information and instant messaging. According to the network and the mobile Internet tools have a lot of advantages such as wide coverage, full function, fast operation, etc., they have been widely used in the daily management of college students.informatization, networking and real-time have become a future development trend of the Management of the College students.It is worth us to do deeper researching and exploring that how to take the advantage to build a optimized rapid and integrated information platform which can be used in the daily management of college students and work of Ideological and political education .

\section{Basic characteristics of network and mobile Internet tools}

"The new media based on the digital technology, the computer network technology and the mobile communication technology have been formed a huge network system, which contains the advantages of a capacity of information, rich resources,Fast transmission ,strong interaction, wide coverage, and diversified forms.

\subsection{Huge content}

The rapid development of the Internet and the mobile Internet tools in recent years which has been increased large information not only though the operation mode but also the rapid development of 
the self media .According to that, we can search and get the information such as pictures and videos as quickly as we can. The counselors can not only search for educational resources as quickly as they can,but also can understand the ideological trends and circumstances of their students in the university.

\subsection{Instant communication}

It is shorten the distance between the people and the people by the rise of the Internet and the mobile Internet tools, and even gradually replaced the traditional way of the contact. In the past time we need to log in on the computer to use the software, and now We can use a mobile phone to use the software,It has truly realized communicate face to face, reduced the costs of communication, improved the efficiency of communication.

\subsection{Information direct}

One of the characteristics of the network media is the information of open and direct,The network media does not need a certain level of the foundation as the traditional media does. No matter what how to express the ideas, the feelings or the emotions, And the mobile Internet tools has made the release of the personal information becomes more simple,and faster.

\section{Opportunities brought by Internet and mobile Internet tools}

3.1 Establish a secure and reliable communication platform for counselors and students

The network and the mobile Internet tools are able to provide a relatively reliable, hidden, point to point two-way communication channels. and because of the counselors and the students communicate through the network and the mobile Internet tools,it is able to enable students to be in a more comfortable and securer communication distance. Network is able to provide an equal, fast, and hidden communication platform, which is able to make students more relaxing when they speak out their feelings to their counselors. Meanwhile it is able to avoid the embarrassment of face-to-face communication and uncomfortable.

At the same time, the application of the mobile Internet tools is able to enable counselors to get the rid of the shackles of time and places, they are able to maintain contact and communication with their students at any time and any places. Moreover, the mobile Internet tools as a new communication tool which is popular among young college students, It is not only can dilution of status and age of the gap between the counselors and the students, but also can virtually to narrow the psychological distance between the counselors and the students.

\subsection{Establish a rich and convenient student information platform}

The mobile Internet tools have the characteristics of information publicity, It is able to provide a richer, more convenient and more efficient information platform for ideological and political education.For example,there are a lot of ways that are able to let the students know the college information,the class affairs, the teaching content, the students' dynamic, etc at the first time,such as Group chat, messages, announcements, sky drives, exhibition spaces and the other functions.at the same time,the counselors also can understand the students' ideological trends in time.It is not only able to conducive to the cultivation of the students' self constraint and the management ability, but also are able to improve the management efficiency and the simplify the management process and the content

At the same time, the student cadres and the backbone students by using the group function, they are able to upload the latest notice of the Institute as quickly as they can,they are able to build their own virtual communities around the scope, they are able to exchange of information expediently and fast ,and they are able to carry out activities with the other students. Furthermore, Because of the instant and the open nature of the internet and the mobile internet platform, It ia able to provides a more fair and open environment for students' affairs, and it is easier to obtain the trust of the students in the university. 


\section{Challenges from the Internet and mobile Internet tools}

\subsection{The challenge of developing students' values}

One of the characteristics of the network is "virtual", The emergence and the development of "virtual reality" has caused great changes in the Communication mode and the interpersonal relationship.In the virtual space of the information and the network,

In the secrecy of virtual reality the students 'speech is not under control ,that will easy to reduce the student's moral standard .In the meantime, If the college students accustomed to live in the virtual world of the network, that will affect their ability to get along with people in the real world and there will be a lack of trust in others and a lack of the self discipline. And further affect the establishment and the development of the basic interpersonal relationship in the future. At the same moment, Network is full of all kinds of thoughts spread, violence, money worship, hedonism, pornography and other negative content,the college students' psychology and the values are not mature enough ,and their ability to identify and judge the network information is not strong enough. Because of that, they are not only easy to indulge in unhealthy web content and difficult to extricate themselves, but also easy to be blinded by false content and be agitated to make extreme behavior.

4.2 For students to focus on the challenges brought about by their studies

The network is like a kaleidoscope, the rich network of information and illustrated contents , which is able to provide students with a new, all-round, mulch-dimensional experiences. By using various media means of the new media, they are able to access to the required information, enjoy the rich content and enjoy the audition during the network, at the same time, the network is able to bring a lot of convenience to college life, such as the emerging electronic shopping, the payment, the savings etc, besides that variety of the mobile games are able to almost be played everywhere in the world. The college students are in the critical period of the personal habits and the concept formation, their self-control ability is poor, they are very easy to indulge in the network virtual environment and inextricably bogged down in. They are satisfied with the virtual personal attributes brought by the network and they are easy to completely out of the natural attributes of the social value, the formation of eccentric, extreme personality. As a result of this the counselors must pay attention to these factors which are around their students.

\section{Conclusions}

Faced with the development and the progress of the times, The irresistible trend, which requires us to recognize the network and the mobile Internet this double-edged sword, Counselor should seize the opportunity to change, they should give full play to the advantages of network, they should make best use of the advantages and bypass the disadvantages, they should seize the forefront of the network era. All in all, Informatization of Ideological and political education in the Colleges and the Universities is the inevitable need for the development of the current situation. In this science and technology society, the counselors need to use modern information technology to do their own work, in order to really make the college students management work with the times.

\section{Acknowledgment}

This research was financially supported by the Scientific and Technological Planning Project of Beihua Uniersity, China.

During the writing process of this paper,Teacher Fangang Meng has given me more and more careful guidance and instruction In the selection of topics and ideas,and I have benefited a lot from these aspects.During the learning process,the teacher 's rigorous scholarship,rich and profound knowledge,sharp academic thinking,working attitude of excellence and studying the indefatigable learning manner are my best role model in my lifelong learning and life.The profound and highly attainments and the rigorous scholarship from mentors will always inspire me. 


\section{References}

[1] Cao Fengcai, Tian Weifei. Thinking of the moral education work of college students in new media era [J]. Journal of North Central University (SOCIAL SCIENCE EDITION), 2008,24 (6): 14-16

[2] Jiang Hong, Xu Jian. Introduction to new media [M]. Shanghai Jiao Tong University press, 2007:4

[3] Luo Fei. The exploration and Reflection on strengthening the management of students in Colleges and universities in the network era. Science and technology and education, 2007472:185.

[4] Hong Pan. Analysis of the opportunities and challenges of the new media in the analysis of the counselors. Urban construction, 2009105

[5] Zheng Yuanjing. Under the new media environment, the effectiveness of Ideological and political education of the theory of [J]. education review. 2011 (11)

[6] Wang Haifeng. On the innovation of Ideological and Political Education under the new media environment [J]. Heilongjiang Education (higher education research and evaluation) 2011 (02).

[7] Qin Xianru. Students' safety awareness education model innovation of the [J] front, 2013 (17)

[8] Chen Guang. Factor analysis and countermeasure research on campus safety and stability of independent college [D]. Tianjin University 2013

[9] Party Huaiwang. Campus security problems of college students [D]. countermeasure research Nanchang University 2013 